\title{
LOS JUDÍOS VALENCIANOS, EL MERCADO Y LAS RUTAS MERCANTILES EN EL MEDITERRÁNEO BAJOMEDIEVAL ${ }^{1 *}$
}

\author{
Juan Leonardo Soler Milla ${ }^{2}$ \\ Universidad de Alicante/Universitat d'Alacant \\ Fundación de Estudios Medievales Jaime II
}

Resumen: Este trabajo constituye una breve aproximación a la actividad mercantil judía valenciana durante los siglos bajomedievales. Para ello se ha realizado un breve repaso sobre la funcionalidad del grupo mercantil judío en las redes de comercio internacional mediterráneas, comparando su protagonismo con los mercaderes cristianos pero sobre todo como la comunidad musulmana, y también su peso en la expansión mercantil del reino de Valencia.

Palabras clave: judíos, musulmanes, cristianos, reino de Valencia, rutas mercantiles, mediterráneo, baja Edad Media.

\footnotetext{
1. *Este artículo es fruto de la intervención realizada en el Congreso Internacional "Entre el Imaginario y la memoria. Aspectos sobre la presencia cultural judia en el pasado y el presente de la Comunidad Valenciana», organizado por la Generalitat Valenciana y la Universidad de Alicante durante los días 27 febrero/1 marzo 2007, 9-11/adar/5767, en la misma ciudad de Alicante. Agradezco al profesor Hinojosa Montalvo haberme invitado a participar en la sesión científica del mismo presentando un trabajo meramente aproximativo y descriptivo, deudor de la historiografía reciente y parcial investigación propia, de un panorama que tenemos que enriquecer historiográfica y documentalmente durante los próximos años.

2. Ayudante del Departamento Historia Medieval, Historia Moderna y Ciencias y Técnicas Historiográficas de la Universidad de Alicante. Y miembro del grupo de investigación: «Poder público, sociedad y cultura en el reino de Valencia, ss. XIII-XV», dirigido desde la Universidad de Alicante por el Prof. Dr. José Vicente Cabezuelo Pliego (dirección URL: http://cvl.cpd.ua.es/ConsPlanesEstudio/ConsGrpInv/datosGrupo. asp?codGrupo=16949).
} 
Abstract: This work constitutes a brief approximation of the commercial jewish activity in Valencia during the late middle age centuries. For that it has been done a brief review about the functionality of the jewish mercantile group in the international commercial network, comparing its prominence with the christian merchants, but above all, as a moslem community and also its weight in the commercial expansion of the Kingdom of Valencia.

Keywords: Jews, muslims, christians, Kingdom of Valencia, commercial routes, Mediterranean, late middle ages.

Samuel Cortell había cambiado su rol habitual, llevaba un tiempo pensando invertir una cantidad de dinero que había almacenado sigilosamente quizá por su actividad crediticia dentro de la comunidad judía de Valencia. Su afán no era otro que obtener un mayor beneficio y aspirar a una riqueza superior que le era restringida en el marco local. En su cabeza rondaba invertir en el tráfico mercantil, es decir, entregar una cantidad para enrolarla en algún periplo que las naves valencianas realizaban a lo largo del mediterráneo. Fue así, a fines de 1326, cuando se asociaba con Bernat Vidal, ambos dos intitulados en estas letras como «mercartori Valencie», mercaderes de la ciudad, inmiscuían un capital no definido pero valorado en 300 espuertas -obviamente se refería a una cantidad determinada, aunque a veces podría ser alzada- en la ruta magrebina ${ }^{3}$. La nave contratada, un leño de orla con 6 marineros a bordo propiedad de Berenguer Amalvi y Berenguer Amorós, también de la ciudad de Turia, partía de esta misma y probablemente haciendo escalas en algunos de los numerosos puertos del sur del país, moteando costa tras costa y surcando playa tras playa, saltaría desde tierras nazaríes al horizonte magrebí, al concurrido mercado de Mostaganem -puerto relativamente cercano a Honein, hoy suelo de Argelia-, así lo estipulaba el notario. Pasas, higos, almendras, un poco de sal y algún que otro productos del fértil agro valenciano, repletaban este barco que, con las preocupaciones oportunas por la acción de piratas, esperarían ser depositadas en este puerto o cualquier otro del Magreb Central. Su recepción era más que exitosa, estos productos constituían artículos de semilujo para las elites norteafricanas; los operadores en suelo musulmán, fueran cristianos, judíos o miembros de la media luna, independientemente de su nacionalidad o su relación socio-profesional, lo conocían.

3. La referencia archivístca se encuentra en A.R.V. P. Not. A. Lappart (10.408 (1326, diciembre, 5); citada y transcrita en Soler Milla, J. L., «Relaciones mercantiles entre Valencia y el Magreb durante la primera mitad del siglo XIV», en Miscelánea Medieval Murciana, XXXVII-XXVIII, Murcia, 2003-2004, pp. 125-157, concretamente en p. 149. 
Poco más sabemos de este contrato negociado por Samuel. Excepto que en una cláusula que nos resulta más que interesante, se recoge que a la vuelta de la nave, esto es, cuando los socios de estos mercaderes -el judío y el cristiano- advirtieran al patrón o por un consenso anterior, de la idoneidad del momento y las mercancías a adquirir para dirigirse a Valencia o Mallorca, no podían embarcar vino. El documento es muy alusivo al respecto: «promitimus etiam -dicen los patrones-que non levabimus et portabimus in dicto ligno aliu vinum judaicum nisi nostri, ne dicti Samuelis », ¿se trataría de vino especial este vinum judaicum?

Obviamente, esta bebida al igual que la carne era preparada según un ritual, unas normas más que arraigadas y desarrolladas en las comunidades hebreas. En el caso del vino, como recuerda Ariel Toaff en un sugesitvo ensayo, el problema era menor que en el abastecimiento cárnico, pues los judíos recurrían al mosto o al vino común con asiduidad ${ }^{4}$. Las comunidades mosaicas no eras muy estrictas y escrupulosas en la preparación y en la distribución de auténtico vino casher, que muchas veces les sería más que difícil recurrir a vendimias mantenidas por ellos mismos, que otras tantas elaboraban a partir de viñas cultivadas por cristianos y que podían tener destino tanto en los propios judíos como en las comunidades cristianas 5 . De hecho, en una fecha tardía como el mismo siglo XVII, el rabi veneciano, León de Modena, observaba con cierto realismo «da quando so distinguere tra la mano desstra e la sinistra, non ignoro che da tempo inmemorabile i nostri padri in Italia erano soliti bere vino comune». Comentario que se puede extender a todos los grupos humanos de Sefarad.

Aunque para tener una imagen más global, fueron muchos los hebreos y sus comunidades las que producían sus caldos (vinos, y derivados como la vinassa, aguardientes) y lo comercializaban en radios locales-comarcales e incluso interregionales ${ }^{6}$. Lo importante de este advertimiento en una escritura notarial cristiana, no lo olvidemos, era la imposibilidad desde el universo mental cristiano de beber ese vino, cosa institucionalmente prohibida y circunstancia, como tantas otras, de segregación entre comunidades.

Unos meses atrás o antes, durante el otoño de 1326, otros dos individuos de la comunidad mosaica valenciana, Salomó Juniç y Salomó Çahal, «juheus Va-

4. ToAfF, A., Il vino e la carne. Una comunittà ebraica nel Medioevo. Bologna. 1989, pp. 59 y ss.

5. J.V. García Marsilla analiza como en la ciudad de Valencia los comerciantes hebreos adquieren las cosechas de los cristianos de la huerta de esta ciudad antes de producirse; y que por otro lado el carácter casher del vino se circunscribe únicamente a la elaboración de mosto. Cf. García Marsilla, J. V., «Puresa i negoci. El paper dels jueus en la producció i comercialització de queviures a la Corona d'Aragó», en «Jueus, conversos i cristians: mons en contacte»; dossier coordinado por Ferran García-Oliver, Revista d'Història Medieval, 4, 1993, Valencia, pp. 169-170.

6. TOAfF, A., «Vida material de la comunitat hebrea en la Italia Tardomedieval», en Jueus, conversos $i$ cristians.., pp. 11-24. 
lencie», habían decidido probar suerte comercializando un producto muy considerado por los hebreos, me refiero al citado vino. Concertaban con Ramon Isern y Bertomeu d'Altet, otros dos patrones muy activos de la ciudad de Valencia, utilizar su nave, otra vez un leño de orla compuesto por 10 marineros, para cubrir la transitada ruta Valencia-Mallorca transportando 300 y 130 jarras llenas de esta bebida, propiedad de los dos judíos respectivamente ${ }^{7}$. Tampoco mucho más podemos atisbar a través de esta letra; simplemente señalar que no nos extraña que se comercialice vino entre estos mercados: era uno de los productos más aclamados en suelo insular durante estas décadas ${ }^{8}$, que no se establece ninguna prohibición en el periplo de regreso y que fuera más que probable que esta mercancía se destinara algún miembro de la aljama hebrea mallorquina. Los lazos familiares y profesionales entre los judíos de uno y otro lugar fueron, asimismo, más que frecuentes.

Estos dos episodios constituyen casos aislados o relativamente específicos de la idiosincrasia y actividad hebrea valenciana dentro de la vitalidad comercial valencianos de inicios del siglo XIV. Objetivamente se trata de dos referencias notariales circunscritas a estas primeras décadas del Trescientos y relativas a expediciones comerciales. Un análisis mayor que he realizado en otro lugar, nos conduce a replantearnos lo siguiente: ¿qué fueron estos dos únicos viajes respecto a los centenares de inversiones que realizaron los mercaderes cristianos durante estos años en el comercio marítimo? e incluso ¿y qué relación guarda con el paulatino despegue de las actividades mercantiles de la otra minoría, los mudéjares, que también participan o comienzan a frecuentar estas rutas? La respuesta queda más que anticipada en el tono y significado de esta cuestión. Si se permiten establecer un porcentaje de la participación de los hebreos en el comercio exterior a principios del siglo XIV, basta con tildarlo de ínfimo ${ }^{9}$. Este carácter

7. La referencia archivísitca se encuentra A.R.V. P. Not, A. Lappart, $\mathrm{n}^{\circ} 2855$ (1325, octubre, 25).

8. Soler Milla, J. L., «Intercambiar y vincularse económicamente en el Mediterráneo Occidental: un ejemplo a través del estudio de las relaciones comerciales entre Valencia y Mallorca durante la primera mitad del siglo XIV», en Jiménez Alcázar, J.F., Ortuño Molina, J., Soler Milla, J. L, Actas del III Simposio Internacional de Jóvenes Medievalistas Lorca 2006, Lorca (Murcia), 2007, pp. 183-189.

9. La evaluación de la documentación notarial de la exhumación de los registros conservados nos lleva a examinar más de tres centenares de instrumentos mercantiles ligados con el comercio exterior (nólits o fletes, comandas, sociedad mercantiles, procuraciones, reclamaciones en la fuente judicial); sólo hallamos estas dos referencias notariales de la minoría judía, más alguna referencia en la cancillería regia o justicia de la ciudad de Valencia, de carácter aislado. Significado casi irrisorio con el potencial que empieza a articular el grupo mercantil cristiano valenciano en este mismo espacio económico, tanto autóctono como de otros países de la Corona de Aragón y extranjeros. Ideas que han sido avanzadas en Soler Milla, J.L., Métodos comerciales y rutas mercantiles maritimas en Valencia durante la primera mitad del siglo XIV. Trabajo de Investigación, Universidad de Alicante. Alicante, 2004; Idem, «Comercio musulmán y comercio cristiano: la actividad de los mercaderes mudéjares y la producción de las aljamas sarracenas. Valencia, primera mitad del siglo XIV», en Anales de la Universidad de Alicante. Historia Medieval, 14, 2003-2005, en prensa, y que 
de minoritario no desaparecerá durante la centuria posterior aunque aumentará al hilo que también crecía el del volumen mercantil negociado por parte de los operadores económicos cristianos.

Sin embargo es necesario realizarse esta pregunta para calibrar el peso económico de las minorías étnicorreligiosas, judíos y mudéjares, en la articulación del mercado local e internacional y su papel en las redes de intercambio mediterráneas. Y para poder vislumbrar dos pautas fundamentales, como ha tratado la historiografía estas cuestiones y como se puede enfocar metodológicamente estos estudios. Veámoslas:

$1^{\circ}$. Porque desde el punto de vista metodológico es muy difícil encontrar trabajos u obras que integren las funciones económicas de las minorías dentro de un todo, es decir, insertas en la sociedad que las ve desarrollarse. Roser Salicrú en un sugerente trabajo presentado durante el IX Simposio Internacional de Mudejarismo, apuntó la necesidad de realizar estudios que analizarán la relación entre si de las actividades comerciales de los tres grupos etnico-religiososas, cristianos, musulmanes y judíos, para determinar con más propiedad el grado de desarrollo o importancia que los grupos marginados tuvieron en la economía cristiana ${ }^{10}$. Dicha carencia también se puede extrapolar al plano social, hecho reiteradamente señalado por historiadores como J.M $\mathrm{M}^{\mathrm{a}}$. Monsalvo desde la década de los ochenta y desde hace algunos años por T. Glick, M. Meyerson, D. Niremberg, B. Catlos y parte de la historiografía anglosajona. Este «vicio metodológico» de la historiografía peninsular consciente o inconscientemente, ha conducido muchas veces a obtener una visión de los grupos marginales como una sociedad paralela o un grupo segregado, sin entrar en otras pautas sociales ${ }^{11} \mathrm{o}$ como grupos descontextualizados de las dinámicas

tendrán su fruto en la tesis doctoral «Mercado y actividad comercial en Valencia durante el siglo XIV: rutas, mercaderes e intercambios», en fase final de elaboración.

10. Una propuesta que puede considerarse más que obvia o superada pero que, a mi juicio, venía justificada por la existencia de un buen número de trabajos que individualizaban en la función de operadores judíos y musulmanes, sobre todo en las rutas mediterráneas -véase el Magreb-, sin contrastarla con la de sus homólogos cristianos. SAlicrú I LLuCh, «Mudéjares y cristianos en el comercio con Berbería: quejas sobre favoritismo fiscal y acusaciones de colaboracionismo mudéjar, una reacción cristiana a la defensiva», en VII Simposio Internacional de Mudejarismo. De mudéjares a moriscos: una conversión forzada, Teruel, 1999, p. 299.

11. Sería interesante describir o enunciar las tres momentos y cuatro «teorías» en el estudio de los minorías étnico religiosas que marcan en buena medida la historiografía ibérica:

$1^{\circ}$. Debate posturas Américo Castro, convivencia y aculturación, Sánchez Albornoz, enfrentamiento y superposición de grupos sociales-civilizaciones.

$2^{\circ}$. Segregación y exclusión social. Visión de sociedad paralela

$3^{\circ}$. Persecución de estas minorías en pro de la uniformización religiosa y la creación del Estado Moderno; línea heterogénea desde Pérez, Suárez hasta Bartlett. 
sociales urbanas, al insistirse únicamente en visiones culturales, sociales y religiosas de los mismos forjadas historiográficamente por el mantenimiento de una identidad conversa, al decir de R. Narbona ${ }^{12}$.

$2^{\circ}$. E intrínsicamente relacionado con lo anterior, no existen muchas investigaciones que hayan focalizado esencialmente sobre las actividades comerciales de los judíos valencianos, sin entrar en la aportación de documentación de fuentes diversas (no sólo las fiscales) y sobre todo considerando el prisma metodológico anterior; comentario que puede ser extensivo a los territorios de la Corona de Aragón. Reconozco otra vez la dificultad de hallar bibliografía específica, dedicada fundamentalmente a estos aspectos. Se pueden reseñar algunos destacados trabajos, sin ánimo de exhaustividad y sin caer en la mera descripción de estudios que analicen meramente las actividades económicas, sin un esquema global o de conjunto. Por ejemplo, los del profesor Tov Assis para la Barcelona bajomedieval ${ }^{13}$, algunos estudios para el ámbito catalán ${ }^{14}$, los documentados artículos de la doctora Blasco para Zaragoza ${ }^{15}$, las aportaciones de López

$4^{\circ}$. Ambivalencia de contrastes socio-políticos, identidades socio-económicas más que étnicas. Enfrentamiento-coexistencia-conveniencia intergrupal (espacios y momentos cambiantes).

La denuncia por parte de Meyerson es manifiesta: «En la perspectiva dominante, las comunidades minoritarias se presentan, o bien como objetos de persecución, o simplemente de forma aislada; en la medida en que su interacción con ellas es considerada, los cristianos son cono frecuencia poco más que autómatas perseguidores llenos de odio», MeYerson, M., «Un reino en contradicciones: Valencia, 1391-1526», en Revista d'història medieval, 12. Los mudéjares valencianos y peninsulares, Valencia (2001-2002), p. 13.

12. Sus palabras son tajantes al respecto: «Los judíos, pero sobre todo los conversos, deben contextualizarse mejor en el medio que por su naturaleza les es propio, el de la sociedad urbana de fines de la Baja Edad Media. Generalmente los estudios sobre judíos y conversos suelen desentenderse de esta situación, o también presentarla desde una perspectiva centrípeta respecto a la historia política, la historia de la Iglesia y la denominada historia de las mentalidades, que tanto se ha desarrollado en los últimos tiempos. La lectura de un número más o menos amplio de este tipo de trabajos tan especializados proporciona la impresión de que los historiadores pretender sostener la idea de grupo a toda costa, insistiendo en visiones culturales, religiosas y sociológicas, y a la vez desentenderse de la complejidad política, social y económica de las ciudades en las que residieron.», vid. NARBOna Vizcaíno, R., «Los conversos de judío. Algunas reflexiones sobre una bibliografía de Historia urbana medieval», en SABATÉ, F., DenJean, C., (Eds.), Chrétiens et juifs au Moyen Âge: Sources pour la recherche d'une relation permanente, Lleida, 2006, la cita en 235, y también pp. 236 y $239-240$.

13. Assis, Yom Tov: «La participación de los judíos en la vida económica de Barcelona, s. XIII-XIV», Jornades d'Història dels Jueus a Catalunya, Ajuntament de Girona, Gerona, 1990, pp. 77-92.

14. Aunque centrada únicamente en el crédito; Oldich i Castanyer, Inmaculada: «Aspectes econòmics de l'activitat dels jueus de Vic, segon el Libri Iudeorum (1266-1278)», en Miscel·lània de Textos Medievals [Barcelona], 3 (1985), pp. 3-118; y SECALL GüELl, Gabriel: «Els jueus mercaders de teixits de Valls, a la primera meitat del segle XIV», Cultura, 418 (1983), pp. 24-26.

15. Entre algunos otros, cf. Blasco Martínez, A. «La producción y comercialización del vino entre los judíos de Zaragoza (siglo XIV)», en Anuario de Estudios Medievales [Barcelona], 19 (1989), pp. 405-449, IDEM, «Corredores de comercio judíos en Zaragoza (1300-1425)», en Anuario de Estudios Medievales [Barcelo- 
Pérez ${ }^{16}$ y más recientes de Tudela y Maiz ${ }^{17}$ para los hebreos mallorquines, los sugestivos trabajos de J.V. García Marsilla ${ }^{18}$ y A. J. Mira Jódar ${ }^{19}$ para algunas comunidades del rural valenciano y los clásicos trabajos de Leopoldo Piles ${ }^{20}$ y Ramón Ferrer ${ }^{21}$, desde las fuentes fiscales y normativas, revisados, ampliados y enriquecidos por J. Guiral ${ }^{22}$ y, sobre todo, J. Hinojosa relativas a la participación de los hebreos en el tráfico exterior valenciano desde fines del Trescientos y a lo largo del Cuatrocientos ${ }^{23}$. Es decir, un panorama historiográfico muy desigual, parcial por cuanto que necesitaría de un mayor vaciado documental y esfuerzo interpretativo, pero relativamente prometedor puesto que urge una ulterior reflexión de conjunto.

na], 29 (1999), pp. 141-173. IDEM, «Los judíos de Zaragoza y el comercio de paños (siglo XIV)», en El món urbà a la Corona d'Aragó del 1137 als decrets de Nova Planta: XVII Congrés d'Història de la Corona d'Aragó Barcelona. Poblet. Lleida, 7 al 12 de desembre de 2000, Vol. 1. Barcelona, 2003, pp. 223-239; IDEM, «Judíos zaragozanos comerciantes de tejidos en el siglo XIV: anotaciones biográficas», en Acta historica et archaeologica mediaevalia, 26, Barcelona, 2005, pp. 587-612.

16. LóPEZ PÉREZ, Ma . Dolores: «El progrom de 1391 en Mallorca y su repercusión en los intercambios comerciales con el Magreb», Actes I Col.loqui d'Història dels Jueus a la Corona d'Aragó, Institut d'Estudis Ilerdencs, Lleida, 1990, pp. 239-260. IDEM, La Corona de Aragón y el Magreb en el siglo XIV (1331-1410), Barcelona, 1995. (Vid. Apartado «La participación de las minorías», pp. 327-346.), IDEM «Los operadores magrebíes en la Corona de Aragón a finales del Trescientos y principios del Cuatrocientos: las actividades mercantiles de judíos y musulmanes norteafricanos», XIV Congresso di Storia della Corona d'Aragona (Sassari-Alghero, 1990), Vol. III, Cagliari, 1996. pp. 558-572.

17. Maíz Chacón, J., Tudela Villalonga, Ll., «Els mercaders jueus mallorquins a meitat segle Xiv», XVIII Congreso de Historia de la Corona de Aragón, Universitat de València - Fundació Jaume II el Just, Valencia, 2005, pp. 1129-1148

18. García Marsilla, J. V., «Puresa i negoci. El paper dels jueus..., op. cit.

19. Mira JódAr, A. J., «Els diners del jueus. Activitats econòmiques d'una familia hebrea al món rural valencià», en Ibídem, pp. 101-126.

20. Piles Ros, Leopoldo: «El dret del Xxe e XXXe (Para favorecer las relaciones comerciales de los judíos nor-africanos con el Reino de Valencia, 1393-1495), en Sefarad, 44, 1984, pp. 218-282.

21. Ferrer Navarro, R., «Los judíos en el comercio valenciano durante el siglo XIV», en Actas I Congreso de Historia del País Valenciano, Vol. II, Valencia, pp. 553-566.

22. Guiral HadZiossiF Jacqueline :«L'apport des communautés juives et musulmanes au commerce maritime de Valence au XVè siécle», en Deuxième Colloque International d'Histoire : Économies méditerranéennes : équilibres et intercomunications. XIIIè-XIVè siècles», Atenas, 1985, pp. 461-474 (reed. «L'aportació de les comunitats jueva i musulmana al comerç maritim de Vàlencia al segle Xv» en Afers, 5/6, (1987), Valencia, pp. 33-46); Idem, Valencia, puerto mediterráneo en el siglo XV (1410-1525). Valencia, 1989. (Vid. Capítulo «La comunidad judía» pp. 449-461).

23. Hinojosa Montalvo, José: «Los judíos en el reino de Valencia durante el siglo xv», Anales de la Universidad de Alicante. Historia Medieval, 3, Alicante, 1983, pp. 143-183; Idem, «Actividades judías en la Valencia del siglo XIV», La ciudad hispánica durante los siglos XIII al XVI (Actas del Coloquio celebrado en La Rábida-Sevilla, 1981), II, Madrid, 1985, p. 1547-1566, Idem, Los judíos en tierras valencianas. Valencia. 1999. (vid. Apartado «Las actividades comerciales» pp. 163-169), Idem, «Las actividades mercantiles de los judíos saguntinos. De Valencia a Granada y Berbería», en Arse, 35 (2001), pp. 101-132. 
$3^{\circ}$. También relacionado con los dos ítems anteriores, hay que reparar en los instrumentos político-institucionales y en el ámbito socio-económico de todos los grupos étnicos que forman parte de la sociedad bajomedieval. Legalmente desde fines del siglo XIII, 1292, a los judíos se les prohibió el comercio con mercaderías importantes ${ }^{24}$. Al marco jurisdiccional le acompañaba la realidad cotidiana; es así como los mercaderes judíos, al igual que los musulmanes, quedaron relegados en el gran comercio internacional a posiciones subsidiarias y se especializaron en determinados productos o mercados (de importancia secundaria). La razón de tal función o espacio tendríamos que buscarla no tanto en la incapacidad de recursos y medios de estos grupos o la desviación de sus inversiones en otros sectores, como en el potencial de los grandes comerciantes cristianos que entorpecían y sobre todo vedaban el acceso y actividad de los hebreos $^{25}$, es una cuestión meramente monopolística.

Por tanto, los judíos encontrarían cierta solvencia económica en la distribución de los excedentes agrarios, alimentos, y como mediadores en algunos intercambios con artículos procedentes de manufacturas, siempre en operaciones de corto radio: local, comarcal y regional ${ }^{26}$. Su mayor actividad, dedicación y profesionalidad la adquirieron con el crédito, el préstamo con interés, además del arrendamiento de rentas reales, señoriales y municipales ${ }^{27}$. Los objetivos de mi estudio no me permiten referirme a estas cuestiones, que han sido trabajadas con intensidad en muchas aljamas, como las del valle del Ebro y el ámbito centroseptentrional valenciano. Sólo convendría indicar que en paralelo al proceso de introducción del crédito urbano en el medio rural, es decir, del desarrollo de

24. Sesión plenaria que prolongaba, asimismo, otra reunión que años atrás-1293. había vedado su participación en la administración. Cf. SHNEIDMAN, J.L. L'imperi catalano-aragonés (1200-1350), Vol. II, Barcelona, 1975, p. 205.

25. Un proceso similar ocurre respecto a la relación de la comunidad cristiana con la mudéjar, sólo que esta última a través de un lento proceso de acumulación de capital mercantil y jerarquización política en el seno de su comunidad, aparecerán algunos mercaderes, dignos de ser comparados con sus homólogos cristianos; ya a fines del siglo xv: tales como los Xupió, Ripoll, Bellvís, cf, entre una amplia bibliografía de Manuel Ruzafa, puede consultar la última síntesis y referencias bibliográficas específicas en RUZAFA GARCíA, M., «La morería de Valencia: centro económico mudéjar en área de convergancia cristiana y musulmana mediterránea», en S. CAVACIOCCHI (Ed.), Relazioni Economiche tra Europa e mondo islamico. Secc. XIIIXVIII. Atti delle XXXVIII ${ }^{a}$ Settimane di Studi dell Istituto Internazionale di Storia Economica «F. Datini», Prato, Le Monnier, vol. I, 2007, pp. 325-338.

26. García Oliver, F., «De Perpinyà a Elx. Desenvolupament econòmic i geografia de les aljames», en $X u$ deus e Conversos Na Idade Media. Santiago de Compostela, pp. 253-256.

27. Uno de los individuos que aglutina todas las actividades reseñadas, desarrollo de instrumentos crediticiosfinancieros y usura, redes política-institucionales clientelares, inversiones comerciales, arrendamientos de impuesto, etc., es Jafudà Alatzar que ha sido biografíado extensa y detalladamente por Jaume Riera, cf. RIERA I SANS, J., «Jafudà Alatzar, jueu de València (segle XIV)», en Jueus, conversos i cristians..., pp. 65-100 
los vínculos de dependencia del marco ciudad-campo, se inserta la actividad prestamista judía que juega un papel más que sustancial ${ }^{28}$ y que también está en relación, por ello me he detenido, en la vehiculación de productos de un lugar a otro. Es el espacio físico, institucional y económico del mercado donde las tres comunidades, musulmanes, judíos y cristianos, interactúan y se relacionan en marco de inferioridad, igualdad, superioridad, interés y conveniencia y definitivamente dependientes ${ }^{29}$, por ello hay que radiografiar un espacio y momento concreto para distinguir estas relaciones económicas ${ }^{30}$ que en nuestro caso se centra en las redes internacionales, sin descuidar las inversiones y las concertaciones de negocio locales, precedentes y causantes de tráfico y operaciones de mayor índole.

\section{UN PRIMER OBSERVATORIO, VALENCIA, PRIMERA MITAD DEL SIGLO XIV}

Volvamos a nuestro primer observatorio. En la Valencia de los inicios del Trescientos, los dos viajes reseñados, llevados a cabo por Samuel y los socios de idéntico nombre, Salomó, más alguna otro resquicio documental de la cancillería regia, como la eximición a Vives Abenvives de ocupar cargos en la aljama valenciana, que residía en tierras norteafricanas ejercitando el oficio de mercaduria en Bugía ${ }^{31}$ y alguna referencia indirecta arribada a la instancia judicial. Estas expediciones sería cuasi anónimos en el ajetreo continuo de la mesa de los notarios que escrituraban las futuras operaciones mercantiles y prácticamente desapercibidas en el trasiego social y económico cotidiano de su puerto. Y esas operaciones se insertan la dinámica habitual en la conexión económica Mallorca y Valencia dominado por los mercaderes valencianos, con densas relaciones y asociaciones mercantiles con sus homólogos mallorquines caracterizada por el intercambio de madera, vino, frutos secos, productos alimenticios hacia las islas

28. Como señala F. García Oliver: «En qualsevol cas, l'activitat hebraica juga un paper remarcable en els lligams de dependència que la ciutat estén sobre el camp, i sobre tot el rerafons dels vincles engegats entorns del fenòmens expansius del mercat és on es desplega el crèdit, no com un tret antroplógic que defineix l'especialització semita sinó com la forma més agressiva que el capital urbà emprá per sotmetre al camperolat», García Oliver, F. «De Perpinyà a Elx...»», p. 254.

29. Hinojosa Montalvo, J., «La inserción social hebrea en al formación social valenciana», en Jueus, conversos i cristians..., pp. 57-61.

30. Por último, es necesario ser muy cautelosos en dichos estudios en relación a dos coordenadas de análisis fundamentales, la espacial y la cronológica. De nuevo Meyerson: «En realidad, tales obras consideran todavía a las minorías de una manera extrañamente descontextualizada, a veces taxonómica, como sí, de algún modo, no les hubiese afectado los cambios socioeconómicos e institucionales experimentados por los cristianos; Meyerson, M., «Un reino en contradicciones..., p. 13

31. A.C.A. Reg. 485 , fol. 260 r-v. (1332, noviembre, 11) 
y éstas ejerciendo su papel de redistribución de los productos de la cuenca occidental mediterránea, sobresaliendo las del mercado sículo-sardo y magrebíi ${ }^{32}$. Por tanto son los comerciantes cristianos, bien del emergente grupo mercantil local, los mercaderes del resto de la Corona de Aragón, fundamentalmente de Barcelona y Mallorca, junto con la frenética actividad de franceses ${ }^{33}$ y la más que destacable de las compañías italianas ${ }^{34}$, quienes administraban la totalidad del tráfico mercantil local. Asimismo, los musulmanes quedaban algo menos relegados que los hebreos de estos grandes negocios participando en algún viaje esporádico y a través de un puñado de licencias reales para cruzar relativamente «protegidos», solo nominal y normativamente el Mediterráneo, radiografían su escasa importancia durante estas décadas ${ }^{35}$.

En cualquier caso la realidad del judío valenciano de esta época nos provoca una visión que contrasta con la minoría judía mallorquina ${ }^{36}$. Ésta, como han puesto de manifiesto los trabajos de López Pérez y Tudela-Maíz, se muestra muy activa durante estas décadas en el comercio mediterráneo. Las referencias a comandas mercantiles y fletes invirtiendo con socios cristianos o magrebíes sobre todo en tierras norteafricanas (puertos de Orán, Honein, Mostaganem, Bona, Bugía, etc.) son muy prolijas en la documentación insular ${ }^{37}$. Y las reclamaciones por imposiciones arbitrarias establecidas en aduanas tunecinas, nos hacen pensar en su asentamiento y radio de actividad en Ifriquiya y sobre todo Tremecén (Magreb Central $)^{38}$. Incluso a través de los registros de cancillería es fácil encontrar como los judíos de Mallorca recalaban en las costas alicantinas, los ejemplos de impagos de lezdas y robos en nuestras costas son numerosos. Por ejemplo, varios judíos mallorquines reclamaban insistentemente desde 1319 unas mercancías robadas por Francesc Carroç cerca del puerto de Alicante al atacar la coca de

32. En dos estudios analíticos que profundizan en las relaciones entre el espacio valenciano con Mallorca y el Norte de África durante estas décadas y que refuerzan tales argumentos: Soler Milla, J. L., «Relaciones mercantiles entre Valencia y el Magreb ..., op. cit., Idem, «Intercambiar y vincularse económicamente en el Mediterráneo Occidental..., op. cit.,

33. Romestan, G., «Els mercaders llenguadocians en el Regne de València durant la primera meitat del segle XIV», en FuRIó, A., Valéncia, un mercat medieval, Valencia, 1985, pp. 175-263

34. Igual Luis, D. Navarro Espinach, G., «Relazioni economiche tra Valenza e l'Italia nel Basso Medioevo», Medioevo. Saggi e rassegne, 20 (1995), pp. 61-67, especialmente.

35. Soler Milla, J. L., «Comercio musulmán y comercio cristiano: la actividad de los mercaderes mudéjares., op. cit.

36. «Si en la ciudad de Valencia comprobábamos una supremacía evidente de la comunidad musulmana respecto a la judía en cuanto al comercio con áreas magrebies y granadinas, en Mallorca ocurre justamente lo contrario». LóPez Pérez, Ma . D., La Corona de Aragón y el Magreb en el siglo XIV (1331-1410), Barcelona, 1995 , p. 327.

37. Maíz Chacón, J., Tudela Villalonga, Ll. «Els mercaders jueus mallorquins..., op. cit.

38. López Pérez, Ma . D., La Corona de Aragón y el Magreb..., pp. 328-329 
los también mallorquines Alomar y Martîn ${ }^{39}$ Décadas más tarde, a mediados de siglo, diversos mercaderes judíos mallorquines, asociados con cristianos, como Mossen Benabriam y Mossen Maleti frecuentan los puertos alicantinos, sobresaliendo Denia haciéndose con vino, alquena, algarrobas y adzebib para transportarlas a Orá, Argel y Bugía ${ }^{40}$. Y también otro destacado testimonio que alude a un embargo realizado a unos judíos mallorquines que transportaban diversas materias tintóreas y alumbre en el Cap de l'Aljub, donde habrían realizado escala para saldar deudas con comerciantes del lugar, realizado por el recolector de las generalidades de Orihuela durante octubre de $1377^{41}$.

Estas expediciones se insertarían, una vez más, en las redes Valencia-Mallorca-Magreb $^{42}$. Los puertos y carregadors de las costas alicantinas, desde Moraira, Teulda, Denia, Calpe, Altea, Villajoyosa, Alicante, Cap del Aljub, La Mata y Cap de Cerver, sirven como escala a las naves mallorquinas para aprovisionarse de

39. A.C.A. Reg. 165. f. 227-v y 228-v-229-r. Reclamación que se prolonga en el tiempo, queda constancia en registros posteriores puesto que la demanda al parecer no se satisface. Alguna noticia anterior de la conexión hebrea-mallorquina valenciana, a partir de la cancillería regia como la petición del monarca Pedro II a los cónsules de Mallorca para que liberaran a Isaac Sibili e 1291. A.C.A. eg. 85, fol. 146, (1291, octubre, 10), en Hinojosa Montalvo, J., En el nombre de Yahveh. La judería de Valencia en la Edad Media. Valencia, 2007, p. 531.

40. Los ejemplos en esta ruta mercantil en MaIz CHACÓN, J., «Los judíos mallorquines en el comercio y en las redes de intercambio valencianas y mediterráneas del medievo», en este mismo dossier; asimismo, otros expediciones mercantiles directas a suelo valenciano, como a Morvedre y Cullera, agradezco al autor haberme facilitado el texto.

41. Noticia recogida en Hinojosa Montalvo, J., «Los judíos en el reino de valencia. Testigos de una historia secular», también en este mismo dossier.

42. Sin ánimo de ser exhaustivo y, dejando de lado los autores que han tratado las relaciones entre los mercados valencianos y mallorquines en el espacio económico del Mediterráneo Occidental, como F. Melis, Ch. E. Dufourcq, M. Del Treppo, A. Riera, M. Tangheroni, J. Guiral, D. Abulafia, P. Iradiel, D. Igual, E. Cruselles, con trabajos suficientemenet conocidos, la biliografía más específica, desde el observatorio valenciano, Hinojosa Montalvo, J. «El consell valenciano y el reino de Mallorca durante la primera mitad del siglo XIV», en XIII Congreso de Historia de la Corona de Aragón, Mallorca, 1989, pp. 85-97; con el análisis de la exportación de coses vedades, y MuÑoz Pomer, R., «Las relaciones comerciales Valencia-Reino de Mallorca a través del Dret de Mercaderia (1411-1412)», desde la fuente notarial vid. SolER MiLLA, J. L., «Intercambiarse y vincularse económicamente en el Mediterráneo..., pp. 187-189 y desde el observatorio insular, Coll JuliÀ, N. «El tràfic maritim amb les illes balears a través d'un notario valencià del segle XV», en Estudis Balearics, 9, Palma de Mallorca, 1983, pp. 27-56; Rosselló VAquer, R., «Comerç entre València i Menorca (1381-1402), en Bolleti de la Societat Arqueològica Lul-liana, 44, 1988, pp. 171-177; CATEURA Benasser, P., «Política, finanzas e infraestructura comercial: Valencia y Mallorca en la primera mitad del siglo XV», en Anuario de Estudios Medievales, 20, Barcelona, (1990), pp. 212-221; Idem, «Valencia y Mallorca en el siglo Xv», en Mayurqa, 26, Palma de Mallorca, 2000, pp. 181-193; BARCELó Crespí, M., «Relació entre els jurats de Mallorca i els de València (1455-1521)» en XVIII Congreso de Historia de la Corona de Aragón, Valencia, 2005, Vol. I pp. 349-359,; entre la extensa bibliografía de M ${ }^{\mathrm{a}}$ D. López, véase el rol de Mallorca en el comercio con el Magreb en LóPez Perez, M ${ }^{\mathrm{a}}$ D., «Mallorca y el Magreb en la Baja Edad Media», en Trillo SAn José, C. (ed.), Relaciones entre el Mediterráneo cristiano y el norte de África en época medieval y moderna. Granada, 2004, pp. 87-226. 
productos ciertos productos agrícolas y sal para repletar sus naves y redistribuirlas en Berbería, un tráfico mercantil muy dominado desde ambos mercados, mallorquín y valenciano, por las comunidades cristianas, bien locales o internacionales, aunque en el primer caso con una notable presencia judía, muchas veces en plena consonancia y asociación con mercaderes cristianos ${ }^{43}$.

Entonces ¿a qué se dedicaban los judíos de esta aljamas? Los judíos de la capital y de las comunidades cercanas, tenían una función similar a los musulmanes, estaban especializados en determinados productos: compraventas de producción agrícola (trigo, arroz de la huerta) y cargas de vendimias (para producción de vino), comercio de este caldo ${ }^{44}$, esporádicamente con paños de Narbona ${ }^{45}$ como los musulmanes del lugar ${ }^{46}$ y seda por parte de las familias más prestigio$\mathrm{sas}^{47}$, productos comprados masivamente por los pañeros y sociedad valencia$\mathrm{na}^{48}$. Llama la atención que la hebreos valencianos recurran a sus compatriotas de las comarcas meridionales, como es el caso de la aljama de Elche para hacerse con esteras de junco; pero se centran principalmente en el crédito, como se ha señalado ${ }^{49}$.

43. Sevillano Colom, F., «Mercaderes y navegantes..., p. 464; LóPez Pérez, Mª D, La Corona de Aragón y el Magreb..., p. 570-571; más recientemente, Idem, «Mallorca y el Magreb en la Baja Edad Media», en Trillo San José, C. (ed.), Relaciones entre el Mediterráneo cristiano y el norte de África en época medieval y moderna. Granada, 2004, p. 165; Soler Milla, J.L., «Relaciones mercantiles en Valencia y el Norte de África..., pp. 138-140, Idem, «Intercambiarse y vincularse económicamente en el Mediterráneo..., pp. 187-189

44. En otros espacios de la Corona de Aragón, el vino fue objeto de control y detención determinante y monopolísitica en algunas aljamas del reino de Mallorca, como Inca, Pollensa y Alcudia, al igual que el aceite y trigo en Monzón: cf. García Marsilla, J. V., «Puresa i negoci. El paper dels jueus..., p. 169, en el segundo caso tomando como base un estudio de M. Á. Motis. Cf. también RichA ABAD, A., «Els jueus de Barcelona i l'aprovisionament de vi entre 1348 i 1391», en La Mediterrània, àrea de convergència de sistemes alimentaris (segles V-XVIII), XIV Jornades d'Estudis Històrics Locals, Palma de Mallorca, 1995, pp. 627-634.

45. Como la deuda que reconocía Jafudá Sibili y Simó Segarra haber contraido con los hermanos Arquejaire, destacada compañía mercantil occitana en Valencia, en 1336. Hinojosa Montalvo, J., En el nombre de Yahveh. La judería..., p. 522.

46. Soler Milla, J. L., «Comercio musulmán y comercio cristiano: la actividad de los mercaderes mudéjares., op. cit.

47. Como la compra de Isaac Abnayub de dos onzas y un cuarto de seda de Turquía para el obrador de Bernat Valldaura, y una deuda de Maluf Xaprut también por adquirir seda. Hinojosa Montalvo, J., En el nombre de Yahveh. La judería..., p. 523.

48. Bordes García, J., «La organización del trabajo en la industria textil valenciana (1238-1350), en JiMÉnEZ Alcázar, J. F. Ortuño Molina, J y Eiroa Rodríguez, J.A.(eds.). Actas I Simposio de Jóvenes Medievalistas, Lorca 2002, Lorca(Murcia). 2003. pp. 33-42, Idem, «Los pañeros valenciano durante la primera mitad del siglo XIV» en XVII Congreso de Historia de la Corona de Aragón (C.H.C.A), Barcelona-Lleida 2000. Barcelona. 2003, pp. 253-265.

49. Una imagen más diferente nos la ofrecen las informaciones de los protocolos notariales de la ciudad del Turia concretamente para el año 1386 que aluden a las adquisiciones por parte de judíos de telas, diversos 
Percepción muy diferente respecto al tamaño y tonalidad de las actividades económicas es la que obtenemos al comparar el grupo mosaico valenciano con los judíos castellanos (de las regiones fronterizas y villas como Guadalajara, Ocaña, Toledo entre muchas otras) que acudían muy frecuentemente a la ciudad de Valencia, adquiriendo paños franceses, de Narbona y Perpiñán, y de la incipiente manufactura valenciana, fruto de un tráfico mercantil más denso y beneficioso que el propio mercado local, entablando relaciones con mercaderes languedocinos y valencianos más relevantes de estos momentos, una situación casi inalcanzable para la mayoría de judíos capitalinos, quienes apenas escapaban del marco económico local durante la primera mitad del siglo $\mathrm{XIV}^{50}$.

De nuevo, podemos observar la relación jerárquica y desigual entre las tres comunidades en el ámbito del préstamo. Un número ingente de musulmanes, provenientes de las comunidades rurales son deudores de algunas familias judías, tales como los Sibili, Xaprut, Abnayub, Alatzar, Morcat y otras tantas, que les anticipan dinero a través de mutui y comandas para cubrir sus deudas, invertir en producción, herramienta agrícola, modestas manufacturas y realizar operaciones mercantiles ${ }^{51}$. Se trata de un préstamo de radio local-comarcal, nivel de capital bajo-medio y de clientela rural, tal y como expuso J. Hinojosa y ha ratificado García Marsilla para la ciudad de Valencia ${ }^{52}$. Sin embargo, el «gran» crédito de la época se encuentra en manos cristianas: las mesas de cambio que

tipos de paños, seda, lana, mercería, aceite, atún y el cotidiano vino a los cristianos: cf. Hinojosa MonTALvo. J., «La inserción social hebrea en al formación social..., p. 59.

50. Además de las abundantes referencias notariales, véase, asimismo, el guiaje y exención de impuestos a de Abrahim Baroly, para llevar cuatro cargas de paños y fustanes valencianos a la corte castellana. A.C.A. Reg. 219, fol. 162-r, (1320, diciembre, 3).

51. J.V. García Marsilla a través de la fuente notarial y judicial ha comprobado la función del crédito judío, lejos de ser mayoritariamente dedicado a la usura, se destinaba a ofrece líquido al campesinado de la huerta -hinterland- de la ciudad de Valencia, un buen análisis en García Marsilla, J. V., Vivir a crédito en la Valencia Bajomedieval. De los origenes del sistema cenal al endeudamiento del municipio. Valencia, 2002, pp. 96-100, en estás páginas se describe la clientela rural de los mismos, así como en un interesante gráfico la distribución territorial del préstamo judaico, p. 99. Asimismo, Antoni Furió ha podido documentar que el crédito judío en la villa de Alzira tenía un carácter local y comarcal alcanzando a toda la villa, los dos ravales y alquerías circundantes, abarcaba a las comunidades cristianas y musulmanas rurales y la clientela era muy variada y amplísima desde el punto de vista socio-profesional: artesanos, mercaderes, notarios, estamentos eclesiástico y campesinos especialmente musulmanes, cf. Furió, A., «Els jueus d’Alzira a la segona meitat del segle XIV», en Jueus, conversos $i$ cristians..., pp. 142-145.

52. Hinojosa Montalvo, J., «El préstamo judío de la ciudad de Valencia en la segunda mitad del siglo XIV», en Sefarad, XLV, 1985, pp. 315-339. García Marsilla, J. V., Vivir a crédito en la Valencia medieval....pp. 85-99. Otro espacio donde se percibe las relaciones dependientes en relación al crédito entre las tres comunidades sería Daroca y sus comarcas. Donde el crédito es fundamental para los musulmanes, destinado a las mismas funciones arriba descritas, pero sus actividades no son comparables a las de sus acreedores -judíos y cristianos-. Ledesma Rubio, Mº.L. Estudios sobre los mudéjares en Aragón..., p. 86. 
plebiscitan las mayores operaciones financieras y de tráfico mercantil tanto con Occitania como con los mercados mediterráneos, las ostentan los cambistas cristianos capitalinos ${ }^{53}$.

Conforme avanza las décadas aumenta muy ligeramente la actividad comercial de los judíos, al menos las fuentes de la segunda mitad del Trescientos, siempre antes de 1391 y desgraciadamente sólo fiscales y no notariales evidencian esta tendencia. De nuevo son los análisis de les coses vedades, los objetos prohibidos a la exportación (por ser materias básicas para el abastecimiento, producción o para no fortalecer a los enemigos políticos, bien cristianos, bien musulmanes) que necesitaba un permiso real (al que le acompañaba una cantidad en metálico que se le satisfacía a la autoridad permanente), los que nos permiten conocer más datos. De la totalidad de asientos de los años 13781387, más de 600 menciones documentales como señala J. Hinojosa, el tráfico judío se orientaba principalmente al reino de Castilla, sobresaliendo el comercio interior-terrestre sobre el marítimo; no en vano la presencia de nuevo de mercaderes judíos en las tierras del Turia era muy relevante. En segundo lugar quedaban los territorios de Aragón, Cataluña y Mallorca y de forma anecdótica Berbería, el norte de África. Los productos exportados eran los comunes que se registraban en estas series y prescripciones reales precedentes; por mar (madera, sebo, cáñamo y pez-pegunta) y por tierra (pequeñas manufacturas elaboradas a partir del metal y quincallería). Los porcentajes estimados en relación con la actividad de los cristianos oscilarían entre el 3 y $10 \%$ del total, cifras que siempre se manejarán ${ }^{54}$. Realidad económica, dibujada solamente por esta fuente documental, que continúa durante las décadas finales del siglo XIV y principios del siglo XV, y que sólo nos muestra una imagen muy fragmentaria del movimiento de puerto de Valencia y su función distribuidora y redistribuidora de los principales objetos y productos que dinamizan los mercados mediterráneos como materias primas, productos alimenticios, cereal, pescado, diversas materias y tintes colorantes, pieles, paños, lanas, seda, aceite, sal, azúcar, especias, frutos secos, entre tantos otros. Función que el mercado valenciano comienza a desarrollar durante las primeras décadas del siglo XIV, gracias a las intensas conexiones económicas en el Mediterráneo occidental, al despegue del grupo mercantil local, a la fuerte presencia comercial de los operadores

53. Garcia Marsilla, J. V., «Crédito y banca en el Mediterráneo medieval: la quiebra del cambista valenciano Francesc de Pals (1316-1319)», en Anuario de estudios medievales, 25, 1995, Vol. 1, pp. 127-149; Idem, Vivir a crédito en la Valencia medieval..., pp. 120-127

54. Hinojosa Montalvo, José: «Actividades judías en la Valencia del siglo xv..., pp. 1554-1559. Los productos derivados del metal eran dedales, agujas, tijeras, botones, anillas, balanzas, cuchillos, dagas, puñales, además de otros como los productos ganaderos, vid. p. 1558. 
franceses y al orientación mercantil del agro ${ }^{55}$ y que se consolidad a fines de la misma centuria ${ }^{56}$.

\section{UN SEGUNDO OBSERVATORIO. VALENCIA, SEGUNDA MITAD DEL SIGLO XV}

Tomemos un segundo observatorio. Descabezado el judaísmo valenciano tras los progroms de 1391, los hebreos se reagruparon en aljamas que fueron protegidas y en cierta forma alentadas por la autoridad monárquica, caso de Morvedre, la actual Sagunto, y en menor medida Xàtiva. La judería de Valencia quedaba muy desestructurada y diezmada por la violencia antisemita, nacía y con el tiempo se desarrollaba un poderoso grupo converso. Nuevos tiempos corrían para el judaísmo valenciano, el testigo de la etapa más o menos floreciente que había vivido la comunidad hebraica de su capital lo tomaba la aljama de Morvedre. Estos cambios tuvieron su correspondencia en el ámbito económico. Por un lado, en la ciudad de Valencia, los judíos tenían una presencia testimonial y no constituyeron casi ningún problema para la autoridad cristiana ${ }^{57}$. De hecho, la presencia de la comunidad hebrea valenciana no desarrolló ningún protagonismo económico, ni comercial, ni crediticio, salvo casos aislados ${ }^{58}$; de lo contrario habrían entrado en contacto, estrechando lazos con los hombres de negocios locales y la pujante colonia italiana a través de la formación de sociedades mercantiles o la participación en el comercio internacional, de signo mediterránea o ya atlántico, muy importante para la

55. Soler Milla, J. L., «Relaciones mercantiles entre Valencia y el Magreb..., pp. 145-147.

56. Entre la amplia bibliografía del observatorio valenciano, destacamos los trabajos de David Igual que han analizado minuciosamente la funcionalidad comercial del puerto valenciano en las redes económicas del Mediterráneo Occidental y ha subrayado que esta función y carácter, en alguno de sus aspectos, es anterior a lo que inicialmente se presumía: IguAL Luis, D., «La difusión de productos en el Mediterráneo y en Europa occidental en el tránsito de la Edad Media a la Moderna», en «Fiere e mercati nella integrazione delle economie europee. Secc. XIII-XVIII». Atti della 32 ${ }^{a}$ Settimana di Studi dell'Istituto Internazionale di Storia Economica «F. Datini», a cura di S. CAVACIOCCHI, Florencia, 2001, pp. 453-494. Idem, «Política y economía durante la Baja Edad Media. El papel de la monarquía en el comercio exterior valenciano», en Los cimientos del Estado en la Edad Media. Cancillerías, notariado y privilegios reales en la construcción del Estado en la Edad Media, ed. por J.A. BArrio BArrio, Alcoy, 2004, pp. 264-267; Idem, «¿Crisis? ¿Qué crisis? El comercio internacional en los reinos hispánicos de la Baja Edad Media», en Edad Media. Revista de Historia, 8, Valladolid, 2007, pp. 203-223

57. Muy lejos quedaba aquel grupo judío del Doscientos y en cierta medida del Trescientos privilegiado por la autoridad monárquica, con cargos y prebendas en la curia y exenciones fiscales. Muy lejos también de la elite judía en numerosas ciudades castellanas que se configuraron como un gran grupo de arrendadores de impuestos, es decir, una clientela que destinaba liquidez al rey castellano.

58. Alguna operación mercantil exterior muy aislada, vid. Hinojosa Montalvo, J., En el nombre de Yahveh. La judería..., pp. 535-536. 
centuria cuatrocentista ${ }^{59}$. Función que si tuvieron judíos castellanos y portugueses quienes, protegidos por sus instituciones, quienes acudían al puerto valenciano aprovechando su vitalidad comercial y funcionalidad redistribuidora ${ }^{60}$.

Por otro lado, los años que transcurren entre 1392 y 1492, a grosso modo el siglo XV, fueron para la aljama de Morvedre un «era de resurgimiento» al decir de M. Meyerson ${ }^{61}$. Los judíos saguntinos obtuvieron la protección política de Alfonso el Magnánimo y vieron a su comunidad florecer demográfica y económicamente. Gozaron de buenas relaciones con los cristianos de Valencia y sobre todo con las tierras castellonenses, donde focalizaron la importancia y extensión de su función crediticia; además desarrollaron una interesante labor en la producción y exportación vinícola ${ }^{62}$. Fruto de todo ellos fue su más que reseñable participación en las rutas marítimas, sobre todo en Berbería y Granada ${ }^{63}$. Probablemente las décadas posteriores a los levantamiento provocaron un decaimiento de la vida urbana judía -reducida anteriormente a la aljama de la capital-, un desarrollo de un judaísmo de carácter rural, comunidades mosaicas que son protegidas e incluso favorecidas por las autoridades regia y municipales, caso de Morvedre, Xàtiva y Castellón y en espacios señoriales, fruto de reagrupamiento demográfico, exenciones fiscales y ventajas económicas, como las comunidades situadas al sur de Xixona, simbolizadas en Aspe ${ }^{64}$. El caso Castellón es significativo, los judíos tienen un papel fundamental en el desarrollo económico durante la segunda mitad del siglo xv, sus dineros y sus productos consolidan y dinamizan las unidades productivas campesinas y las empresas artesanales familiares. A. J. Jódar demuestra que la familia de los Legem personifica perfectamente la actividad económica judía en este espacio, tejen redes comerciales de índole local y comarcal (Villarreal, Borriana, Vilafamés, Nules, además de su propia vi1la), tienen una variada clientela socioprofesional, dominada por labradores y en

59. En los dos estudios más sólidos sobre la formación de los grupos mercantiles valencianos e italianos para la primera y segunda mitad del siglo XV, a grandes rasgos, a partir de las mesas notariales de Vicent Çaera y Joan Salvador, no tenemos constancia de la participación de judíos en ningún sentido, bien en la relación con las principales familias mercantiles, su composición socioprofesional y su redes clientelares, Cruselles Gómez, E., Los mercaderes de Valencia..., pp. 57-98., y en los fletes entre una de las rutas más importantes para la ciudad, los espacios económicos de Valencia-Liguria y Valencia-Toscana y Lacio, Igual Luis, D., Valencia e Italia en el siglo XV. Rutas, mercados y hombres de negocios en el espacio económico del Mediterráneo occidental, Castellón, 1998, pp. pp. 328-336 y 379-388., por poner dos ejemplos.

60. Hinojosa Montalvo, J., En el nombre de Yahveh. La judería..., pp. 535-537.

61. Meyerson, M., On an Iberian Frontier: The Jews of Morvedre: 1248-1492. Pricenton 2006, pàssim; Idem, «Un reino en contradicciones: Valencia, 1391-1526», Revista d'Història Medieval, 12, Valencia, p. 22

62. Meyerson, M., «Un reino en contradicciones..., p. 23.

63. Hinojosa Montalvo, J., «Las actividades mercantiles de los judíos saguntinos..., p 117-132.

64. Soler Milla, J. L., Los judios de Aspe en la Edad Media. Notas e imágenes de una comunidad olvidada, en prensa. 
menor proporción artesanos textiles y otros sectores (molineros, herreros, sector servicios y viudas) y a la función crediticia unen su papel como intermediarios y redistribuidores de la producción agrícola ${ }^{65}$.

Imagen diferente nos ofrece el grupo converso. Los conversos llegaron a formar una verdadera elite económica que presionaba a las instituciones políticas, reales y municipales, que arrendaba impuestos y que especulaba en determinados ámbitos mercantiles, es decir, que estaba inserta en una intensas relaciones sociales urbanas ${ }^{66}$. Muchos de estos individuos aprovecharon la coyuntura para trazar caminos familiares y estrategias sociales que les diferenciara de sus antiguos correligionarios, resquebrajándose redes familiares, otros las mantuvieron por tiempo, pero no hubo una tendencia o conducta homogénea ni una asimilación repentina a una nueva formación social que resultaba difícil, más que imposible ${ }^{67}$. Se trataba de opciones personales y en este universo tenemos que considerar también sus actividades económicas. Por ejemplo, E. Cruselles al analizar los orígenes socioprofesionales del grupo mercantil valenciano durante la primera mitad del siglo $\mathrm{XV}$, ha podido identificar 28 conversos entre los años $1400-1425$ y solo uno en los años posteriores, 1425-1450 entre la concurrida clientela del notario Vicent Çaera formado por mercaderes, artesanos y operadores de otros lugares del reino de Valencia, la Corona de Aragón, Francia e Italia, además de otros agentes económicos en menor medida, entre un total 302 perfiles personales examinados ${ }^{68}$. De hecho, la conversión de muchos no respondía a una estrategia de reproducción del capital y económica familiar, sino más bien un motivo de cambio para muchas familias cuya posición social podía mantenerse y consolidarse. De lo contrario, los judíos de permanecer en su status socioreligioso implicaba seguir manteniendo las mismas relaciones sociales definidas por la violencia y el rechazo social y el desclasamiento y la inestabilidad económica. Por eso mismo, muchos optaron por la conversión como «su tabla de salvación y abandono de un grupo social que experimentaba una trayectoria social descendientes de imprevisibles

65. Mira JódAr, A. J.: «Els diners del jueus. Activitats econòmiques..., 108-125, quien en este detallado estudio, a partir de la fuente judicial, se radiografía con exactitud el protagonismo mercantil judío, a través del estudio de los Legem durante varias generaciones, 1422-1492, en el comercio, agrícola o de cualquier tipo, y en el préstamo en relación con la villa cristiana, trazando una clara tendencia por la cual la familia consolidad su función como prestamistas., vid. gráficos 6, 7, 8 y 9 .

66. Entre la amplia bibliografía del problema converso en el reino de Valencia, véase por la realización de un verdadero esfuerzo en la puesta al día historiográfica y planteamiento de nuevas perspectivas de estudio: Narbona Vizcaíno, R., «Los conversos de judío. Algunas reflexiones.., op cit.

67. Interesante reflexiones en CASTILlo SAINZ, J., «De solidaritats jueves a confraries de convesrsos: entre la fossilització i la integració d'una minoria religiosa», en Jueus, conversos i cristians..., pp. 192-194.

68. El análisis de la formación, renovación endogámica y reproducción social del grupo mercantil cristiano se puede ver en Cruselles Gómez, E., Los mercaderes de Valencia en la baja Edad Media (1380-1450). Lérida. 2001, pp. 88-98 y gráfica en 99. 
consecuencias ${ }^{69}$. Conversos que se relacionaban comercialmente con los judíos magrebíes haciendo de puente e intermediarios en el comercio entre Valencia y Norte de África a fines del s. XIV e inicios del s. XV ${ }^{70}$.

Un conocido exponente de los mismos fue Jaume de Santángel, quien 1479 fue nombrado baile de Alicante, en 1491 accedió a la bailía general de Orihuela, pleiteó con prohombres alicantinos sobre la recolección de impuesto de signo comercial, se vinculó económicamente con señores y mercaderes meridionales y arrendó las salinas de la Mata, cuyo producto fue anhelado por las colonias genovesas, pudiendo enrolarlo en las principales rutas comerciales mediterráneas y atlánticas generándole unos réditos extraordinarios ${ }^{71}$.

Otro universo social de lo que estamos refiriendo podría ser Husua Toquea, judío de Gandía, que conoce una trayectoria vital muy intensa marcada por las alteraciones sociales de fines del siglo XIV. Los Husua representaban a los mercaderes modestos, si los comparamos con sus homólogos cristianos, pero que lideran el grupo de poder hebreo local, con una estrategias familiares contundentes, y tenían una función vital para la economía comarcal, al poseer una intensa actividad comercial, inversiones mercantiles a través de comandas, ventas de paños, vinos, ganado, actuar como proveedores de la aljama local y administradores de capital a los menestrales y campesinos locales, incluso a la nobleza a partir del préstamo con usura. Las redes económicas de su empresa familiar, como esboza

69. Ibídem, pp. 84-86 y 94, donde describe minuciosamente las conversiones de más de dos decenas de familias desde fines del s. XIV y llama la atención que la segunda generación había consolidado patrimonio y estrategias económicas similares a los cristianos. Por tanto, por lo que nos interesa en estas líneas, los conversos podría tener una participación destacada en el mercado local y quizás en el tráfico internacional, aunque habría que analizar sus redes socioeconómicas y que tipo de tejido mercantil articulan. Cuestiones que el profesor E. Cruselles tiene en curso de investigación.

70. Hecho que ha sido puesto de manifiesto por la doctora López Pérez a través del análisis de las sociedades mercantiles entre conversos valencianos (Gabriel Ballester, Nicolau Valldaura y Pau Massanam por ejemplo) con los judíos magrebíes en las plazas de Orán y Honein: cf. LóPEz PÉrEZ, Ma . D., «Los operadores magrebíes en la Corona de Aragón a finales del Trescientos y principios del Cuatrocientos: las actividades mercantiles de judíos y musulmanes norteafricanos», en XIV Congresso di Storia della Corona d'Aragona (Sassari-Alghero, 1990), Vol. III, Cagliari, 1996. pp. 563-566.

71. Hinojosa Montalvo, J., «Los Santàngel en tierras alicantinas», en VV.AA., Lluís Santàngel i el seu temps (Congrés Internacional. València, 1987), Valencia, 1992, pp. 43-54; BÉnitez SÁnchez Blanco, R., «El valencià Lluís de Santàngel», en $I D E M$, pp. 221-243. En las tierras meridionales valenciana, en la ciudad de Orihuela, tenemos un grupo converso formado por 5 o 6 familias, de profesiones variadas, al que desde inicios del siglo xv se le fue acosando desde la esfera religiosa por su contacto con el grupo judío, desde la introducción de la insaculación, -1445, a una de las más importantes familias se les marginó a la bolsa de ciudadanos menores; dañando sus posibles aspiraciones y estrategias socioeconómicas de promoción social, persiguiéndoles finalmente la inquisición. Vid. BARRIO BARRIO, J.A., «Los judeoconversos Hispanos y su problemática inserción en la sociedad cristiana urbana peninsular», en LoPEs De BArros, M.F. Hinojosa Montalvo, J. (eds.), Minorias étnico-religiosas na Península Ibérica. Períodos medieval e moderno, Évora, 2008, pp. 239-258; Idem, «Los judeoconversos en la frontera sur del reino de Valencia (ss. XIV-XV), en este mismo dossier. 
F. García-Oliver, sobrepasaban en el espacio de la Safor y alcanzaban otros espacios como la Ribera, la vall d'Albaida y la Marina Alta ${ }^{72}$. La conversión provoca que algunos judíos poderosos, caso de los Husua, puedan no solo mantener patrimonios y actividades económicas, liberados de cualquier estigma social, sino diversificarlas y engradecerlas; como demuestran las numerosas deudas que diferente individuos de la sociedad rural contraen con la empresa familiar liderada por Husua, ahora conocido Joan de Cabrera, sus intensos intercambios de tierras y la continuidad en las actividades especulativas ${ }^{73}$.

Si comparamos de nuevo este observatorio con el mallorquín, podemos entender que también los pogromos de 1391 -los levantamientos antisemitas- desarticularon el call de Mallorca sin que llegara a desaparecer. El golpe a la economía mallorquina fue ciertamente importante ya que el papel de esta minoría (sobre todo por su relación con sus colegas magrebíes) en el comercio mediterráneo que se proyectaba desde la isla era fundamental, como han señalado todos los autores (Kriegel, Macaire, Santamaría) ${ }^{74}$. Sin embargo, independientemente de la conversión masiva de los judíos mallorquines y la erección de una seminueva comunidad mosaica alimentada por los componentes del otro lado del Mediterráneo, el Magreb, los judíos siguieron comerciando en esta ruta ${ }^{75}$. Prueba de ello son los guiatges (aunque tenían a veces un carácter protector) y la existencia de algunas compañías mercantiles entre judíos y judeo-conversos ${ }^{76}$.

Pues bien, ¿cómo se tradujo estas transformaciones específicamente en el comercio marítimo valenciano durante el Cuatrocientos? De nuevo la fuente fiscal nos arroja luz en este sentido y, asimismo, tenemos que relacionar la actividad de judíos con mudéjares y cristianos. Martín el Humano llevó a cabo una política de salvaguarda a ambas comunidades, musulmanes y judíos, otorgándoles

72. Garcia-Oliver, F., «Història d'Husua», en R. Narbona et Alit., L'Univers del prohoms, Valencia, 2005, pp. 57-81. Idéntica función que los Legem en Castellón, que «en empreses familiar o associats en companyes, lubrifiquen les bases productives de la explotació agrària i del obrador artesà», Ibídem, p. 80.

73. Ibídem, pp. 81-91.

74. Alguno de ellos de forma más que exagerada, caso de Santamaría Arández, «los judíos venían siendo el alma de la negociación mallorquina en Berbería, el mercado número uno del intercambio mercantil de la isla»; un buen análisis de los hechos señalados más arriba en LóPEz Pérez, Ma . D., La Corona de Aragón y el Magreb..., pp. 328-329

75. Aunque también el papel de intermediarios que habían ejercido entre operadores magrebíes y norteafricanos fur claramente disminuyendo a tenor de la documentación examinada; cf. LóPEz PÉREZ, Ma., «Los operadores magrebíes en la Corona de Aragón a finales del Trescientos..., pp. 567-568. Idea que contradice la expuesta por J. Guiral que plantea el papel de enlace de la comunidad judía de Mallorca respecto a la actividad de los comerciantes norteafricanos en tierras de la Corona de Aragón a tenor de algunas compañías mixtas (catalanoaragoneses y magrebíes) cf. Guiral Hadziossif J., «L'aportació de les comunitats jueva i musulmana..., pp. 42-43.

76. Muestra de ello son los guiatges, los pagos de lezdas, los fletes y las referencias a sociedades. López Pérez, Ma. D., La Corona de Aragón y el Magreb..., pp. 331-346. 
salvoconductos para ir «a terra de moros», como se recoge en los documentos, es decir, Granada y Berbería, siempre que no portaran objetos vedados; política que continuaría el Magnánimo. Estas licencias que se conocen con el nombre de guiatges en la documentación y que oficializaban los viajes de estos individuos respondían a varios motivos: uno, deseo de hacer un negocio, es decir, trayecto comercial pero también por causas familiares, sociales e intelectuales: dos, reencontrase un amigo, tres, recoger herencias, cuatro, aprender a leer y escribir, quinto, cultivarse, y sexto, ir en peregrinaje. Es interesante destacar en estos momentos, que muchos de estos musulmanes y judíos encontraron en aquella «terra de moros», como les gustaba recordar a la autoridad cristiana de sus países de residencia, es decir la Corona de Aragón, una comunidad lingüística, familiar, cultural y religiosa que consideraban una verdadera patria ${ }^{77}$.

Estas licencias nos ofrecen unos datos muy concisos para dos etapas, los años que conciernen 1452-1465 y 1465-1491, a grandes rasgos la segunda mitad del siglo XV, publicadas por J. Guiral pero que posiblemente un estudio más cuidadoso y de otros registros haría variar los números que vamos a ofrecer aunque muy poco probable que el significado de la función económica del las minorías en las redes mercantiles mediterráneas que se tejen y articulan desde el espacio valenciano. Predominan los viajes terrestres sobre los marítimos (los primeros con la vecina Murcia y tierras castellano-manchegas que no describiremos puesto que la variedad merceológica difiere de la mediterránea) ${ }^{78}$. En cuanto a los últimos, los periplos marítimos, vierten una cifra cercana al $10 \%$ de las licencias que se conceden a los judíos, frente al $90 \%$ a los musulmanes en esta primera fase en la que se realizan 30 viajes por año. En la siguiente, los trayectos crecen a la cifra de 42 viajes anuales, pero en lo que respecta a los hebreos su porcentaje disminuye al 1'8\%. Los productos exportados también son los típicos de estos intercambios, las naves eran completadas por sedas, tejidos (pañería local de fácil salida en los mercados coloniales), calderería y la afamada cerámica de Paterna y Manises. Y los puertos más frecuentados eran de occidente a oriente: Granada, Almería, Orán, Honein, Mostaganem, Alger y Túnez ${ }^{79}$.

77. Probablemente estos lugares se sentirían menos extranjeros, aunque tampoco podamos caer en una imagen idílica de entendimiento y convivencia. Cf. Guiral Hadziossif J., «L'aportació de les comunitats jueva $i$ musulmana..., pp. 37-38 y 41 .

78. Las productos exportados entre estos mercados eran variados: materias primas (minerales: hierro, cobre, plomo, estaño, acero), fibras textiles (cáñamo) y armas, cuchillos, quincallería y algún artículo de lujo (vajillas, anillos, collares, dagas enguarnecidas de oro) cf. Hinojosa Montalvo, J., Los judios en tierras valencianas. Valencia. 1999. p. 163-164; un relación mas detallada en Idem. En el nombre de Yahveh..., pp. 534-535.

79. Guiral Hadziossif J., «L'aportació de les comunitats jueva i musulmana..., pp. 36-38; Hinojosa Montalvo, J., Los judios en tierras..., pp. 162-163 y 166. 
De nuevo, el contraste de este comercio marítimo con el tráfico mercantil que conectaba todos los puertos y carregadors de la franja marítima valenciana con su capital, que revelan una extraordinaria variedad merceológica ${ }^{80}$, como se constata en los manifests o peatges de mar, y el que se proyectaba desde la ciudad del Turia con las principales ciudades portuarias y mediterráneas, fruto de la concertación de fletes, seguros y compañías marítimas, es más que manifiesto.

Estas estimaciones cuantitativas, señaladas más arriba, que sólo tienen en cuenta el tráfico contraído por las minorías, no pueden obviar de nuestro análisis el control de la ruta del Magreb, ya sea desde Valencia o Mallorca, esto es, de la Corona de Aragón, por parte de los mercaderes cristianos de uno y otro lugar; que, por otro lado, en aquellos mercados, considerados coloniales desde la óptica occidental, luchan, asimismo, con otras potencias occidentales: genoveses y en menor medida castellanos, franceses y venecianos para controlar las redes económicas. En este sentido, el rol de las minorías en el comercio exterior se puede sintetizar en que se trata de viajes puntuales que en la mayoría de los casos no están sustentando por estrategias y estructura administrativa, salvo esporádicamente algunos caso del linaje musulmán de los Xupió y poco más ${ }^{81}$, que si poseían los comerciantes cristianos a través de los recursos de las compañías comerciales y el paraguas institucional de la Corona.

Las minorías étnico-religiosas tienen que ser estudiadas de forma conjunta entre ellas y su relación con la mayoritaria atendiendo a criterios de diversidad y heterogeneidad económica, ésta, me parece, es la única modo de superar la imagen de un grupo aislado e inconexo dentro de la sociedad. Además desde un punto de vista teórico, B. Catlos ha llamado la atención sobre la diversidad socio-económica de las relaciones intergrupales, más allá de los tópicos historiográficos de judíos prestamistas, musulmanes tenentes y deudores y cristianos dueños o acreedores: «cristianos, musulmanes y judíos se mezclaban unos con otros de manera simultánea en un conjunto de esferas: en la tributación, como tenentes y dueños de tierras,

80. Para no extender la cita, cf. desde un punto de vista general valenciana en Guiral-Hadzilossif, Valencia, puerto mediterráneo en el siglo XV (1410-1525), València, 1989; pp. 48-70; específicamente de un región económica, en Igual Luis, D., Soler Milla, J. L., «Una aproximació al comerç marítim de les comarques castellonenques (segles XIII-XV)», en Millars. Espai i Història, 29 (2006), pp. 104-132, y desde el ámbito mediterráneo, una revisión historiográfica reciente, en IGUAL LuIs, D., «Operadores económicos y espacios de comercio en el Mediterráneo Occidental (siglos XIII-XV)», en este mismo volumen.

81. Los Xupió realizan durante ansacciones comerciales, fletan naves, arrienda impuestos, negocia importantes operaciones de crédito, tienen la gestión política de la aljama y fuertes lazos económicos con los autoridades cristianas. Unas estrategias, redes y vínculos que nos hacen equipararlo a un verdadero hombre de negocios de la época, cf. RuZAFA GARCíA, M, «Ali Xupió, senyor de la moreria de Valencia» en, VV.AA., L'Univers del prohoms, Valencia, 1995, pp. 137-173. 
acreedores y deudores, productores y consumidores, administradores y subordinados; por no mencionar una amplia variedad de contextos sociales $\rangle^{82}$.

Por último, me gustaría finalizar resaltando que la exigua participación de estas minorías, o mejor dicho de algunos individuos en las rutas mercantiles mediterráneas responde al dominio por parte del grupo mercantil cristiano de las redes económicas que se tejieron desde la Corona de Aragón con el sultanato de Granada a lo largo del s. XV o desde este mismo solar con el Magreb durante también los siglos bajomedievales. Ideas y análisis que se hacían eco y en parte corroboran las impresiones de M. Meyerson, quien destaca la escasa incidencia de los mudéjares en el comercio internacional; y que necesitarían tener una continuidad en el análisis de otros espacios, operadores y coyunturas económicas y cronológicas ${ }^{83}$. Hipótesis que formulaba y que aplicaba a la ruta del Magreb pero que se puede hacer ostensible perfectamente a otros espacios y rutas mercantiles del espacio occidental del Mediterráneo y también al ámbito atlántico, al menos desde el mercado valenciano. J. V. García Marsilla ha sido tajante al respecto en el ámbito del tráfico de alimentos: «La minoria jueva, per tant, no tingué prácticamente cabuda dins aquest gran comerç internacional d'aliments, monopolitzat pel mercaders cristians mes acabalats, $i$ el seu paper hagué de redü̈r-se las microespais, las intercambis de curt radi, que enllaçaven el centre urbà ama la seva periferia rural inmediata» ${ }^{84}$, argumento que se puede extender al tráfico exterior de materias primas, productos textiles y la variada gama merceológica que se redistribuye del mercado valenciano desde las primeras décadas del Trescientos, como se ha pretendido examinar en estas líneas. Sin embargo, el protagonismo judío, desde un enfoque global, debe tenerse en cuenta a la hora de conocer las rutas mercantiles que se construyeron desde suelo valenciano en los espacios económicos del Mediterráneo, en el que se imbricaban y fluían personas, naves, mercancías, pensamientos a lo largo de sus dos cuencas y de sus múltiples riberas.

82. Catlos, B., «Contexto y conveniencia en la Corona de Aragón: propuesta de un modelo de interacción entre grupos étnico-religiosos minoritarios y mayoritarios», en Revista d'Història medieval, 12. Los mudéjares valencianos y peninsulares, Valencia (2001-2002), Valencia, 2002, p. 261; de forma más divulgativa en Idem, «Cristians, musulmans i jueus a la Corona d'Aragó: un cas de conveniència», en L'Avenç, $\mathrm{n}^{\circ}$ 263, Barclona, 2001, pp. 8-16.

83. En estas mismas páginas la citad autora consideraba, estando de nuevo acuerdo con su exposición, el dominio por parte del grupo mercantil cristiano de las redes económicas que se tejieron desde la Corona de Aragón con el sultanato de Granada a lo largo del s. Xv, gracias a sus investigaciones o desde este mismo solar con el Magreb durante el siglo xiv, y por los trabajos de Mª.D. López Pérez.; R. SALICRÚ i LLuch, «Mudéjares y cristianos en el comercio con Berbería: quejas sobre favoritismo fiscal y acusaciones de colaboracionismo mudéjar, una reacción cristiana a la defensiva», en VII Simposio Internacional de Mudejarismo. De mudéjares a moriscos: una conversión forzada, Teruel, 1999, p. 299, nota 44.

84. García Marsilla, J. V., «Puresa i negoci. El paper dels jueus..., p. 168. 